\title{
Fine structure in the inter-critical heat-affected zone of HQ130 super-high strength steel
}

\author{
LI YAJIANG*ं', WANG JUAN ${ }^{\dagger}$ and LIU PENG ${ }^{\dagger}$ \\ *National Key Laboratory of Advanced Welding Production Technology, Harbin Institute of Technology, \\ Harbin 150001, P.R. China \\ ${ }^{\dagger}$ Key Laboratory of Liquid Structure and Heredity of Materials, Ministry of Education, Shandong University, \\ Jinan 250061, P.R. China
}

MS received 8 October 2002

\begin{abstract}
The microstructure in the inter-critical heat-affected zone (ICHAZ) of HQ130 steel, has been investigated by thermo-simulation test, SEM and TEM. The problem of toughness decrease in the ICHAZ $\left(T_{\mathrm{p}}=\mathbf{8 0 0}^{\circ} \mathrm{C}\right)$ as well as the effect of $\mathrm{M}-\mathrm{A}$ constituent and carbide precipitation on brittleness was analysed. The test results indicated that the microstructure in the ICHAZ of HQ130 steel was mostly a mixture of lath martensite (ML) and granular bainite (Bg) with a fine but nonuniform grain structure. The cause of brittleness in the ICHAZ was related to production of the M-A constituent in the local region and carbide precipitation. By controlling the welding heat input carbide precipitation and the formation of the M-A constituent can be avoided or decreased.
\end{abstract}

Keywords. High strength steel; heat-affected zone; M-A constituent; fine structure.

\section{Introduction}

In several grades of high strength steels, because of the associated lowering of ductility, it is quite important to ensure the safety of the welded structures. The toughness decrease in the heat-affected zone (HAZ) of the low carbon quenched-and-tempered steel was paid close attention by many researchers (Yajiang et al 1996; Hongyang et al 1997; Zengda et al 1999). The present study is concerned with the brittleness of the coarse grained heataffected zone as investigations of the inter-critical heataffected zone (ICHAZ) are very few. The thermo-simulation test indicated that the toughness decrease in the ICHAZ $\left(T_{\mathrm{p}}=800^{\circ} \mathrm{C}\right)$ of HQ130 steel was more serious than the brittleness of the quenched coarse grained region (Yajiang et al 1996). Therefore, it is important to examine the effect of variations in the microstructure and performance of the peak temperature $A_{\mathrm{c} 1} \sim A_{\mathrm{c} 3}$, and to explore the main factors responsible for toughness decrease in order to control the microstructure and toughness in the ICHAZ $\left(A_{\mathrm{c} 1}\right.$ and $A_{\mathrm{c} 3}$ being 730 and 910, respectively are the feature temperatures of phase transformation).

In this paper, the microstructure and performance of the peak temperature $A_{\mathrm{c} 1} \sim A_{\mathrm{c} 3}$ in the ICHAZ of HQ130 steel have been investigated by thermo-simulation test, scanning electron microscopy (SEM) and transmission

*Author for correspondence electron microscopy (TEM). This study offers an experimental base to determine the best welding parameters.

\section{Experimental}

The tensile strength of grade HQ130 steel is about 1300 $\mathrm{MPa}$. The phase transformation temperatures of this steel are $A_{\mathrm{c} 1} 730^{\circ} \mathrm{C}, A_{\mathrm{c} 3} 850^{\circ} \mathrm{C}, A_{\mathrm{r} 1} 562^{\circ} \mathrm{C}, A_{\mathrm{r} 3} 754^{\circ} \mathrm{C}$ and $\mathrm{Ms}$ $400^{\circ} \mathrm{C}$. The steel was quenched from $920^{\circ} \mathrm{C}$ and tempered at $250^{\circ} \mathrm{C}$. The chemical composition and the mechanical properties are shown in table 1 .

The impact toughness in the simulated HAZ of HQ130 steel was determined by the thermo-simulation test. The dimension of the thermo-simulation specimen was $10 \times 10 \times 55 \mathrm{~mm}$. The peak temperature $\left(T_{\mathrm{p}}\right)$ was at $1350^{\circ} \mathrm{C}, 950^{\circ} \mathrm{C}, 800^{\circ} \mathrm{C}$ and $700^{\circ} \mathrm{C}$, respectively corresponding to the quenched coarse grained region, the fine grained region, the ICHAZ and the sub-critical tempered region. The cooling time $\left(t_{8 / 5}\right)$ from $800^{\circ} \mathrm{C}$ to $500^{\circ} \mathrm{C}$ of the simulated HAZ was $5 \mathrm{~s} \sim 40 \mathrm{~s}$, and the test process was controlled by a computer program. Weld joint was prepared by $\mathrm{CO}_{2}$ gas shielded arc welding. The thickness of the test plate was $12 \mathrm{~mm}$. The welding parameters are shown in table 2.

Specimens were cut from the welded joint region for metallographic examination. The microstructure in the HAZ, especially in the ICHAZ, was observed by means of optical microscopy under different welding heat inputs $(E)$. The microhardness in the ICHAZ was measured using microsclerometer employing a load of $25 \mathrm{~g}$ and a load 
Table 1. Chemical composition and mechanical properties of HQ130 steel.

\begin{tabular}{|c|c|c|c|c|c|c|c|c|c|}
\hline \multicolumn{10}{|c|}{ Chemical composition (wt.\%) } \\
\hline $\mathrm{C}$ & $\mathrm{Si}$ & Mn & Mo & $\mathrm{Cr}$ & $\mathrm{Ni}$ & B & $S$ & $\mathrm{P}$ & $\mathrm{C}_{\mathrm{eq}}$ \\
\hline $0 \cdot 18$ & $0 \cdot 29$ & $1 \cdot 21$ & $0 \cdot 28$ & $0 \cdot 61$ & $0 \cdot 03$ & $0 \cdot 0012$ & $0 \cdot 006$ & $0 \cdot 025$ & $0 \cdot 586$ \\
\hline \multicolumn{10}{|c|}{ Mechanical properties } \\
\hline & $\begin{array}{l}\text { rength } \\
\text { a) }\end{array}$ & \multicolumn{2}{|c|}{$\begin{array}{l}\text { Yield strength } \\
\sigma_{\mathrm{s}}(\mathrm{MPa})\end{array}$} & $\begin{array}{c}\text { Elongation } \\
\delta_{5}(\%)\end{array}$ & \multicolumn{2}{|c|}{$\begin{array}{c}\text { Section contraction } \\
\psi(\%)\end{array}$} & \multicolumn{2}{|c|}{$\begin{array}{l}\text { Hardness } \\
\text { HRC }\end{array}$} & $\begin{array}{c}\text { Impact work } \\
\text { Akv (J) }\end{array}$ \\
\hline \multicolumn{2}{|c|}{1370} & \multicolumn{2}{|c|}{1313} & 10 & \multicolumn{2}{|c|}{43} & \multicolumn{2}{|c|}{$40 \cdot 5$} & $64\left(20^{\circ} \mathrm{C}\right)$ \\
\hline
\end{tabular}

Table 2. Welding parameters used in the test.

\begin{tabular}{lccccc}
\hline Sample no. & $\begin{array}{c}\text { Welding current } \\
(\mathrm{A})\end{array}$ & $\begin{array}{c}\text { Welding voltage } \\
(\mathrm{V})\end{array}$ & $\begin{array}{c}\text { Welding speed } \\
\left(\mathrm{cm} \cdot \mathrm{s}^{-1}\right)\end{array}$ & $\begin{array}{c}\text { Welding heat input } \\
\left(\mathrm{kJ} \cdot \mathrm{cm}^{-1}\right)\end{array}$ & Shielded gas \\
\hline 01 & 170 & 25 & $0 \cdot 44$ & $9 \cdot 6$ & $\mathrm{CO}_{2}$ \\
02 & 170 & 25 & $0 \cdot 26$ & $16 \cdot 0$ & $\mathrm{CO}_{2}$ \\
03 & 180 & 25 & $0 \cdot 20$ & $22 \cdot 3$ & $\mathrm{CO}_{2}$ \\
\hline
\end{tabular}

time of $12 \mathrm{~s}$. The microstructure, relative phase content and grain size were analysed quantitatively by means of a computer controlled micro-image analyser. The microstructure in the ICHAZ, especially the distribution of M-A constituent and carbide precipitates, was further analysed by the JXA-80 scanning electron microscope (SEM) and the H-800 transmission electron microscope (TEM).

\section{Results and analysis}

\subsection{Width and microhardness of ICHAZ}

The microstructure in the HAZ of HQ130 steel was analysed using computerized micro-image analyser. The boundaries of various regions in the weld joint zone were delineated by optical microscopy, and the width was measured by micro-image analysis (see table 3 ).

The width of the ICHAZ of HQ130 steel increased with increase in the welding heat input $(E)$. So controlling the $E$ can reduce the width of ICHAZ from $A_{\mathrm{c} 1}$ to $A_{\mathrm{c} 3}$. The microhardness was measured by using the Shimadzu type microsclerometer, for different $E \mathrm{~s}(9.6 \mathrm{~kJ} /$ $\mathrm{cm}, 16.0 \mathrm{~kJ} / \mathrm{cm}$ and $22.3 \mathrm{~kJ} / \mathrm{cm})$. The microstructure in the ICHAZ and the distribution of microhardness in the HAZ are shown in figure 1 . The test results indicate that when $E$ is small, the high cooling rate results in fine microstructure and high microhardness in the HAZ. Using the same $E$, the microhardness enhanced remarkably from the coarse grained region to the fine grained region. Owing to the heterogeneity of the ICHAZ, the microhardness decreased.

\subsection{Image analysis in the ICHAZ}

When the ICHAZ is heated quickly from $A_{\mathrm{c} 1}$ to $A_{\mathrm{c} 3}$, the temperature is in the range for formation of the upper banite $(\mathrm{Bu})$. During fast cooling, the formation of granular banite $(\mathrm{Bg})$ is favoured. When the cooling rate is relatively slow, the $\mathrm{Bu}$ and the $\mathrm{Bg}$ are formed easily. Under condition of larger heat input, some $\mathrm{M}-\mathrm{A}$ constituents are observed in the ICHAZ, with the $\mathrm{Bu}$ and $\mathrm{Bg}$ formed (see figure 2a). M-A constituents would lead to brittleness and have large influence on toughness.

Some irregular structures with island shape (M-A constituent), distributed in the ferrite matrix and grain boundaries in the ICHAZ, can be observed under SEM. Most of the $\mathrm{M}-\mathrm{A}$ constituents are distributed on the Bg-ferrite boundary, but a few are seen inside the grains. Further analysis indicated that there are two M-A constituents: strip and block (see figure $2 \mathrm{~b}$ ). The strip $\mathrm{M}-\mathrm{A}$ constituent is distributed in the lath of fine-grained ferrite, and the block $\mathrm{M}-\mathrm{A}$ constituent is concentrated on the grain boundaries.

When $E$ is low $(9.6 \mathrm{~kJ} / \mathrm{cm})$, a few of the strip M-A constituents are distributed in the ICHAZ. When larger $E$ $(22.3 \mathrm{~kJ} / \mathrm{cm})$ is used, the M-A constituents consist of the strip and block M-A constituents, but more are of block type. The block M-A constituent has great influence on toughness decrease, and hence should be avoided in the ICHAZ.

For different $E$ values, the microstructure, relative phase content and grain size in the ICHAZ were analysed by means of the XQF-2000 micro-image analyser (see table 4 ). The data are presented in table 4 which shows that the effect of $E$ on grain size in the ICHAZ is small. This is because the peak temperature to be measured $\left(T_{\mathrm{p}}=\right.$ $A_{\mathrm{c} 1} \sim A_{\mathrm{c} 3}$ ) was nearly the same, but the $E$ had greater influence on the content of the M-A constituent. In table 4 , the M-A constituent volume content, $V_{\mathrm{f}}$, refers to the ratio of the area of the $\mathrm{M}-\mathrm{A}$ constituent and the total area. The fine M-A constituent content, $S V_{\mathrm{f}}$, refers to the $V_{\mathrm{f}}$ values where the aspect ratio (the ratio of length to 
width) is larger than 4 (Hongyang et al 1997). The $V_{\mathrm{f}}$ and $S V_{\mathrm{f}}$ of the M-A constituents have important influence on fracture properties.

The results of the micro-image analysis indicated that the welding heat input $(E)$ has marked effect on the volume content, $V_{\mathrm{f}}$, of $\mathrm{M}-\mathrm{A}$ constituent, but does not have much effect on $S V_{\mathrm{f}}$. It is easy to transform austenite into $\mathrm{Bu}$ and $\mathrm{Bg}$ by increasing $E$. Therefore, the content, $S V_{\mathrm{f}}$, of the fine $\mathrm{M}-\mathrm{A}$ constituent is stable relatively.

\subsection{Effect of toughness decrease in ICHAZ}

The test result of the thermo-simulation indicated that the impact energy in the simulated ICHAZ $\left(T_{\mathrm{p}}=800^{\circ} \mathrm{C}\right)$ is relatively low (see figure 3 ), even lower than the toughness of the quenched coarse grained region $\left(T_{\mathrm{p}}=1350^{\circ} \mathrm{C}\right)$. The impact on the sub-critical tempered region $\left(T_{\mathrm{p}}=\right.$ $700^{\circ} \mathrm{C}$ ) is quite high, which can be understood in terms of the microstructure in the region.

Table 3. The results of calculation and measurement on width of various regions in the HAZ of HQ130 steel.

\begin{tabular}{|c|c|c|c|c|c|c|}
\hline \multirow{2}{*}{$\begin{array}{l}\text { Welding heat } \\
\text { input }\left(\mathrm{kJ} \mathrm{cm}^{-1}\right)\end{array}$} & \multicolumn{2}{|c|}{$\begin{array}{l}\text { Quenched region }(\mathrm{mm}) \\
\quad\left(1520 \sim 850^{\circ} \mathrm{C}\right)\end{array}$} & \multicolumn{2}{|c|}{$\begin{array}{l}\text { ICHAZ }(\mathrm{mm}) \\
\left(850 \sim 730^{\circ} \mathrm{C}\right)\end{array}$} & \multicolumn{2}{|c|}{$\begin{array}{l}\text { Tempered region }(\mathrm{mm}) \\
\quad\left(730 \sim 300^{\circ} \mathrm{C}\right)\end{array}$} \\
\hline & Calculation & Measurement & Calculation & Measurement & Calculation & Measurement \\
\hline $9 \cdot 6$ & $2 \cdot 14$ & $2 \cdot 00$ & $0 \cdot 80$ & $0 \cdot 7$ & $2 \cdot 77$ & $2 \cdot 9$ \\
\hline $16 \cdot 0$ & $2 \cdot 50$ & $2 \cdot 25$ & 0.92 & 0.92 & 3.85 & $4 \cdot 1$ \\
\hline $22 \cdot 3$ & $2 \cdot 77$ & 2.52 & $1 \cdot 21$ & 1.08 & 4.73 & $4 \cdot 80$ \\
\hline
\end{tabular}
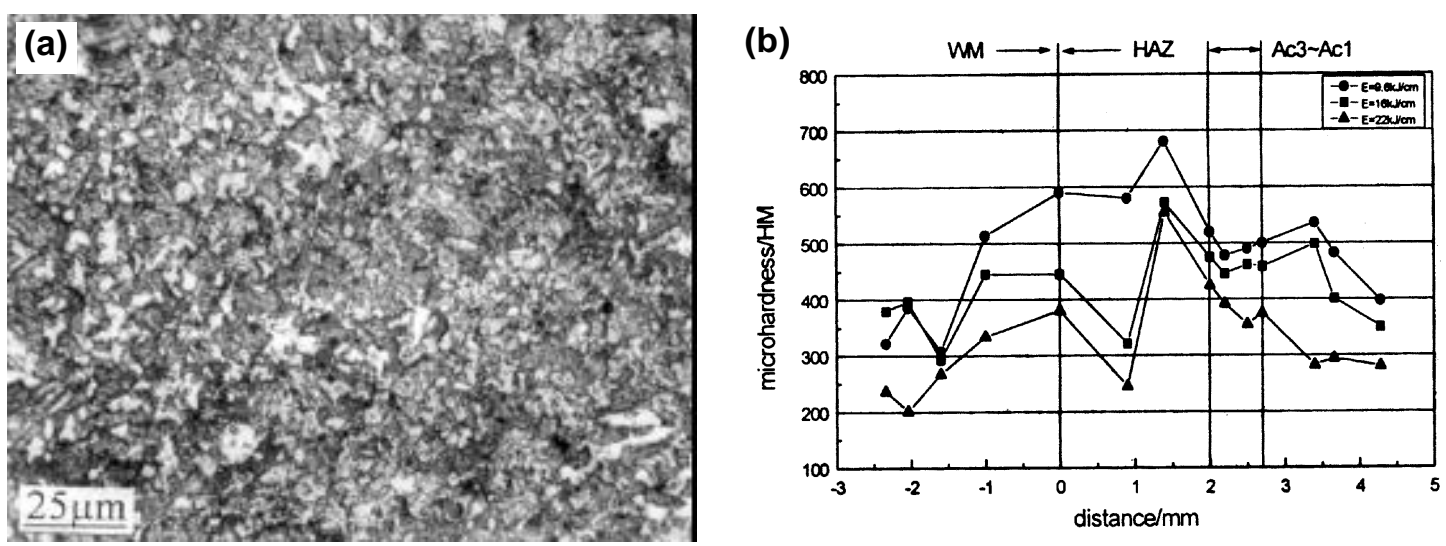

Figure 1. The microstructure and distribution of microhardness in the HAZ of HQ130 steel: (a) microstructure in the ICHAZ $(\times 400)$ and $(\mathbf{b})$ distribution of microhardness in the HAZ.
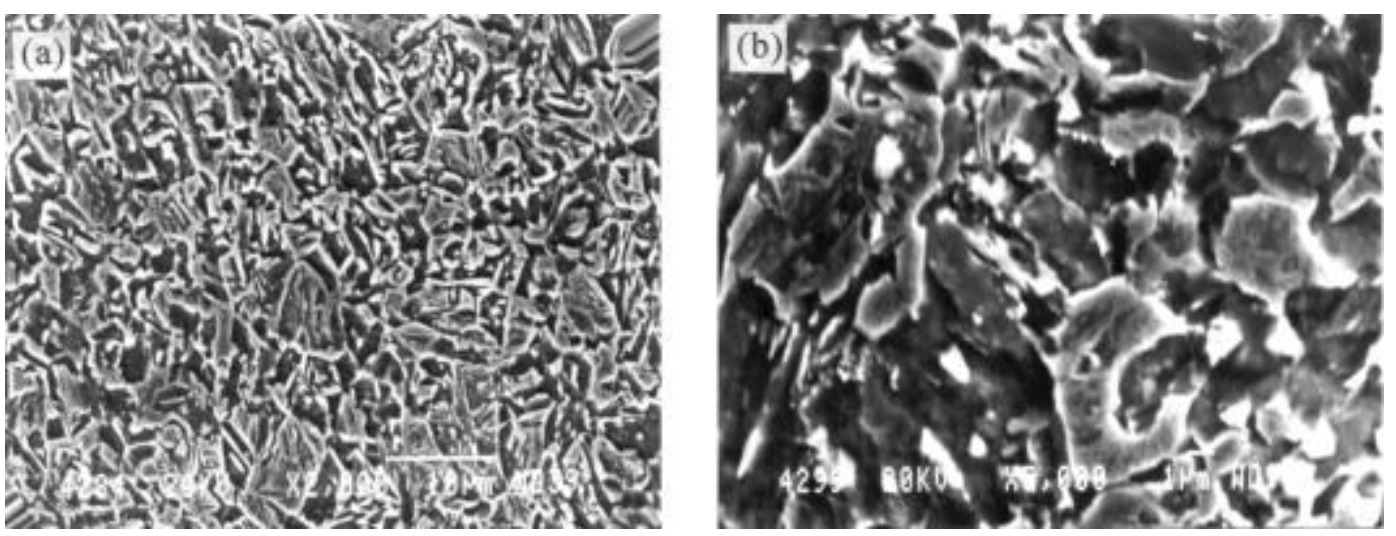

Figure 2. The morphology of the $\mathrm{M}-\mathrm{A}$ constituents in the inter-critical heat-affected zone (SEM): (a) $\diamond 2000$ and (b) $\diamond 5000$. 
Table 4. Microstructure and grain size in the $A_{\mathrm{c} 1} \sim A_{\mathrm{c} 3}$ region of HAZ for HQ130 steel.

\begin{tabular}{|c|c|c|c|c|c|}
\hline \multirow{3}{*}{$\begin{array}{l}\text { Welding heat } \\
\text { input }\left(\mathrm{kJ} \cdot \mathrm{cm}^{-1}\right)\end{array}$} & \multicolumn{5}{|c|}{ Content of microstructure (\%) } \\
\hline & \multirow[b]{2}{*}{$\mathrm{F}(\%)$} & \multirow[b]{2}{*}{ ML (\%) } & \multicolumn{2}{|c|}{ M-A constituent $(\%)$} & \multirow{2}{*}{$\begin{array}{l}\text { Grain degree } \\
\text { (grade) }\end{array}$} \\
\hline & & & $V_{\mathrm{f}}$ & $S V_{\mathrm{f}}$ & \\
\hline $9 \cdot 6$ & $46 \cdot 24$ & $52 \cdot 1$ & 1.54 & 1.03 & $6 \cdot 8$ \\
\hline 16 & $26 \cdot 88$ & 67.64 & 5.48 & 1.42 & $7 \cdot 1$ \\
\hline $22 \cdot 3$ & $21 \cdot 3$ & $66 \cdot 54$ & $12 \cdot 16$ & 1.56 & $7 \cdot 3$ \\
\hline
\end{tabular}

(a)

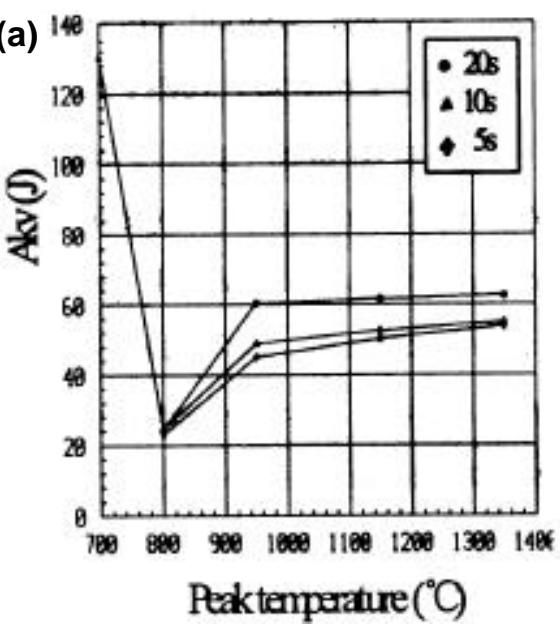

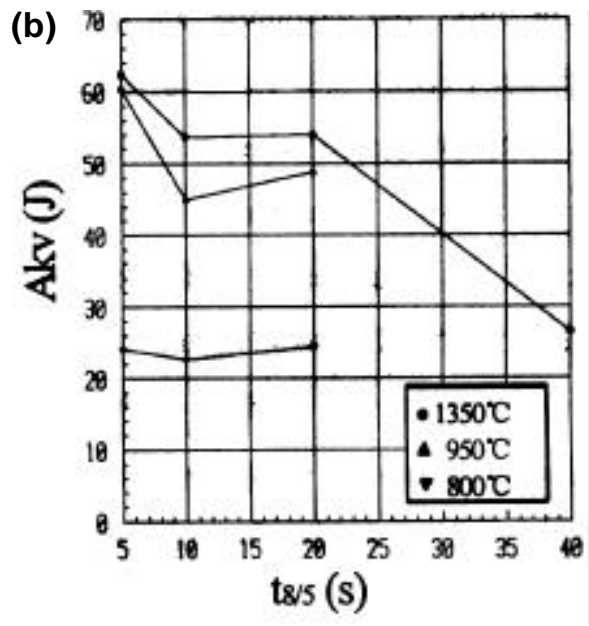

Figure 3. The effect of peak temperature $\left(T_{\mathrm{p}}\right)$ on impact toughness in the simulated HAZ: (a) Relation between $T_{\mathrm{p}}$ and impact work and (b) effect of $t_{8 / 5}$ on impact work.

The ICHAZ is located in the partially transformed region, in which a part of the microstructure transformed into the austenite. The mixtures of fine $\mathrm{ML}+(\mathrm{Bg}+\mathrm{Bu})$ were formed after cooling, but no phase experienced the high temperature temper. Since the hold time of ICHAZ was short, complete homogeneity of austenite was not attained. Especially there were a lot of carbide forming elements in HQ130 steel such as Cr, Mo, B etc. Thus, the dissolving of the alloy carbide was inadequate with some carbide precipitates still in the boundary, which led to toughness decrease. The dominant factor of brittleness in the ICHAZ $\left(T_{\mathrm{p}}=800^{\circ} \mathrm{C}\right)$ is related to the M-A constituent. The microhardness of the $\mathrm{M}-\mathrm{A}$ constituent is higher than that of the surrounding ferrite matrix. This difference in the hardness easily produces stress concentration.

When the microstructure in the ICHAZ is cooled from the austenitic state, fine grained ferrite first forms, which increases the carbon content in the residual austenite. When cooled to $400 \sim 350^{\circ} \mathrm{C}$, the carbon content of the residual austenite would be $0.5 \sim 0.8 \%$. When cooled to a temperature in the region $300 \sim 350^{\circ} \mathrm{C}$, part of the residual austenite would separate out from the lath austenite or the twin martensite and forms the $\mathrm{M}-\mathrm{A}$ constituent (Li Yajiang et al 2001). The condition of the M-A constituent formed in the ICHAZ is similar to that of $\mathrm{Bu}$ (the medium cooling rate). During transformation of austenite into ferrite, carbon atoms diffuse into the austenite phase and the peak concentration of carbon is in the $\alpha / \gamma$ boundary. The chemical composition of the M-A constituent, analysed by electron probe microanalysis (EPMA), is shown in table 5.

The results of EPMA indicate that the content of $\mathrm{Si}, \mathrm{Cr}$ and Mo in M-A constituent is slightly lower than that of the surrounding ferrite matrix; however, the content of $\mathrm{Mn}$ and $\mathrm{Ni}$ is higher. The $\mathrm{Mn}$ and $\mathrm{Ni}$, ferrite stabilizing elements, were rich in the $\mathrm{M}-\mathrm{A}$ constituent.

The morphology of the M-A constituent is one of the factors influencing cleavage fracture. We define $d_{\mathrm{M}-\mathrm{A}}$ as the "effective diameter" of the largest circle that can be inscribed in the M-A constituent. The $d_{\mathrm{M}-\mathrm{A}}$ can be determined by means of SEM. The test results indicate that $d_{\mathrm{M}-\mathrm{A}}$ is in the range $0.5 \sim 1.0 \mu \mathrm{m}$. The magnitude of $d_{\mathrm{M}-\mathrm{A}}$ of the M-A constituent determines the tendency to cause cleavage fracture. When the $d_{\mathrm{M}-\mathrm{A}}$ is larger than some critical value, even if the external loading is not too large, it is easy to cause high stress region, micro-crack propagation and cleavage fracture. It is, therefore, important to make measurements of $d_{\mathrm{M}-\mathrm{A}}$ and to devise treatments to control the effective diameter of the $\mathrm{M}-\mathrm{A}$ constituent. 
The test results indicate that $d_{\mathrm{M}-\mathrm{A}}<1.0 \mu \mathrm{m}$ could meet the requirement to improve toughness.

Whereas during fast cooling, the $\mathrm{M}-\mathrm{A}$ constituent in the ICHAZ of HQ130 steel influences the toughness, it is the presence of carbides along the lath in the boundary that has large influence on toughness during slow cooling (Ikawa et al 1980). To examine the relationship between carbide precipitation and fracture, thin foils were prepared from the ICHAZ region and analysed by TEM and electron diffraction technique.

The presence of carbides along the ML direction was observed by TEM (see figure 4). Two kinds of diffraction spots, ferrite and $\mathrm{Fe}_{3} \mathrm{C}$, appeared in the electron diffraction. This indicates that the toughness decrease in the ICHAZ is related to carbide precipitation near the boundary. The directional carbide among the lath martensite provides low-energy channels of impact rupture, which increases the tendency for brittle fracture. The morphology and dimension of carbide have large influence on brittleness. The carbide precipitates of the fine granular morphology, distributed on the boundary and inside the grain, are favourable to improve the toughness. The $\mathrm{Fe}_{3} \mathrm{C}$, distributed on the boundary, would cause brittleness in the ICHAZ.

Table 5. Chemical composition of M-A constituent and surrounding matrix.

\begin{tabular}{lccccc}
\hline & \multicolumn{5}{c}{ Element (\%) } \\
\cline { 2 - 6 } Measurement location & $\mathrm{Si}$ & $\mathrm{Mn}$ & $\mathrm{Cr}$ & $\mathrm{Mo}$ & $\mathrm{Ni}$ \\
\hline M-A constituent & 0.39 & 1.75 & 0.60 & $0 \cdot 20$ & $0 \cdot 045$ \\
Surrounding matrix & 0.48 & 1.69 & 0.66 & 0.30 & 0.030 \\
\hline
\end{tabular}

The carbide in the lath martensite precipitated along the $(100)_{\text {ML }}$ plane. The dimension of the carbide varied from several nanometers to decade's nanometer. Measurements indicate that the ML lath and the strong plane of $\varepsilon$-carbide are related as $\left([001]_{\varepsilon} / /[110]_{\mathrm{ML}}\right)$. When $T_{\mathrm{p}}=800^{\circ} \mathrm{C}, \varepsilon$-carbide inside $\mathrm{ML}$ lath was dissolved and formed $\mathrm{Fe}_{3} \mathrm{C}$. The $\mathrm{Fe}_{3} \mathrm{C}$ appeared in different directions in the same field of vision. The result of the trace line analysis indicated that the habit plane of $\mathrm{Fe}_{3} \mathrm{C}$ was $(110)_{\mathrm{ML}}$ in figure $4 \mathrm{a}$.

The carbides present on the boundary reduce the fracture strength of the interface. The cracks in the neighbourhood of the carbides, formed by tensile stress, propagate along crystallographic planes, thus causing brittleness fracture. The more the carbide, easier is the crack nucleation. The dominant factors of brittleness in the ICHAZ are the dimension and distribution of the carbide. When $E$ is small $(9.6 \mathrm{~kJ} / \mathrm{cm})$, the carbide is distributed inside ML. When $E$ is larger $(22.3 \mathrm{~kJ} / \mathrm{cm})$, the carbide nucleation and growth are easy. Controlling $E$ can facilitate reduction of carbide precipitation and bring about improvement in toughness in the ICHAZ. From the viewpoint of avoiding cold crack, the heat input should be larger. But when $E$ is too large, the microstructure consists of $\mathrm{Bu}$ or $(\mathrm{Bu}+\mathrm{Bg})$ which leads to decrease in the toughness. For HQ130 steel of $12 \mathrm{~mm}$ thickness, the heat input in the $\mathrm{CO}_{2}$ gas shield arc welding $E=10 \sim 20 \mathrm{~kJ} / \mathrm{cm}\left(t_{8 / 5}=10 \sim 20 \mathrm{~s}\right)$ is required to avoid brittleness.

\section{Conclusions}

(I) The ICHAZ ( $T_{\mathrm{p}}$ from $A_{\mathrm{c} 1}$ to $A_{\mathrm{c} 3}$ ) of HQ130 super-high strength steel exhibits a tendency to brittle fracture. When the heat input $(E)$ of $\mathrm{CO}_{2}$ gas shield arc welding
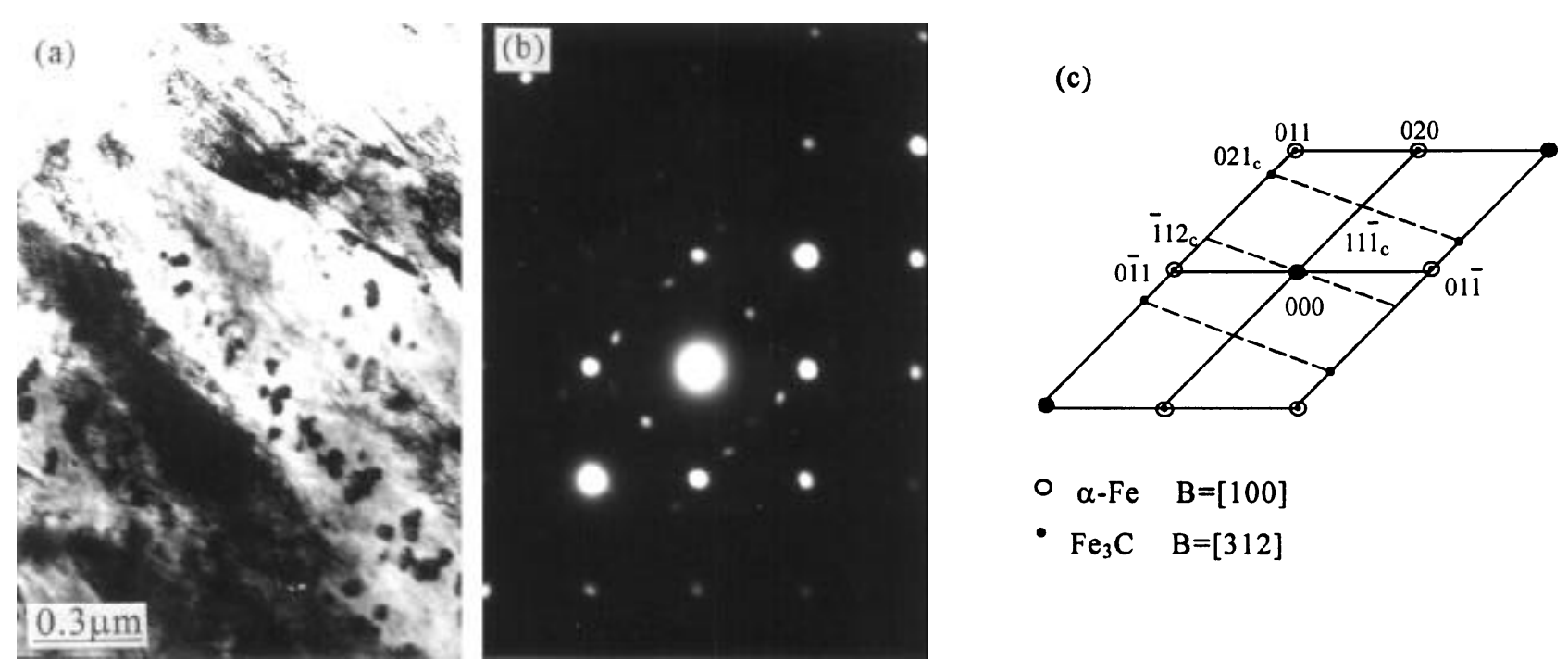

Figure 4. Fine structure in the ICHAZ region of HQ130 steel: (a) TEM morphology $(\times 30,000)$, (b) electron diffraction pattern and (c) schematic diagram index. 
was $9.6 \sim 22.3 \mathrm{~kJ} / \mathrm{cm}$, the width in the ICHAZ was about $0.7 \sim 1.1 \mathrm{~mm}$. Using medium heat input $(E=16.0 \mathrm{~kJ} / \mathrm{cm})$, resulted in the width in the ICHAZ of about $0.9 \mathrm{~mm}$, and the microhardness was about HM450.

(II) The micro-image analysis indicated that the microstructure in the ICHAZ was predominantly a mixture of the lath martensite (ML) and granular bainite $(\mathrm{Bg})$ in which the grains were fine and small, but not homogeneous. When the $E$ was larger, it was easy to produce the $\mathrm{M}-\mathrm{A}$ constituent. The heat input had large influence on the volume content of the $\mathrm{M}-\mathrm{A}$ constituent. By decreasing the content of $\mathrm{M}-\mathrm{A}$ constituent and the effective diameter $\left(d_{\mathrm{M}-\mathrm{A}}<1.0 \mu \mathrm{m}\right)$, the impact toughness in the ICHAZ can be improved.

(III) The reasons of the brittleness in the ICHAZ of HQ130 steel were not only the M-A constituent, but also the carbide precipitates along the ML lath direction in the boundary. The carbide precipitation can be avoided or decreased by controlling the heat input $(E=10 \sim 20 \mathrm{~kJ} /$ $\mathrm{cm})$, so the toughness in the ICHAZ can be improved.

\section{Acknowledgement}

The work was supported by the Foundation of the National Key Laboratory of Advanced Welding Production Technology, Harbin Institute of Technology, and the National Foundation of the Natural Science (No. 50071028), People's Republic of China.

\section{References}

Hongyang J, Lixing H and Yufeng Z 1997 Trans. China Weld. Inst. 1837

Ikawa H, Oshige H and Tanoue T 1980 Trans. Jap. Weld. Soc. 113

Yajiang L, Zengda Z, Zhunian C and Xing W 1996 Acta Metall. Sinica 32532

Yajiang L, Zengda Z, Huiqiang W and Juan W 2001 Trans. China Weld. Inst. 2254

Zengda Z, Yajiang L and Shike Y 1999 J. Mater. Sci. Technol. 15555 